Theories \& Applications, the International Edition

Printed Version: (ISSN 2090-5262)

Online Version: (ISSN 2090-5270)

July 2013, Volume 3, No. 2 Pages (1 - 14)

\title{
Sport and Society: Sociological Aspects of Physical Activity
}

\author{
Aleš Sekot*
}

\begin{abstract}
We are living a time when society, culture and science have become increasingly aware of the great importance of physical activity and sport not only as a part of mass culture, but broadly understood, for individual and social health and well-being. Physical activity of people plays increasingly more important role in scientific interest regarding way of life of contemporary society and it is very important factor in the process of officiating of the level of healthy and active life style, quality of life and health in general. Indispensable role of physical activity in the course of human life is permanently scientifically confirmed also in context of prevention of obesity.

The development of a sedentary life style is the result of a socialization process towards physical inactivity developed in youth and continued into adulthood. At the present we face in our cultural settings apparent tendency: People are more and more individualized, loosing beneficial impacts of community activities, involved in passive way of life lacking proper level of physical activities and active sport. The Czech Republic is on the level of mass sport strongly influenced with the existence of new development of the city structure, including fitness centres, cyclo paths, roller skates stadiums, beach volleyball playing fields, golf courses. The national support of sport is, nowdays, divided into the support of top sports, performance sports and new waves in sports (e.g. sport s for everyone - for all), sports for school, which are then on the regional level (and by the various sport organizations) subsidized from other sources and, moreover, not co-ordinately.
\end{abstract}

Keywords: Physical activity, sport, obesity, society, socialization, built environment.

\section{General Situation}

$\mathrm{T}$ he transformation from industrial to an information society since the1960st and fueled big advances in computer technology cause in Europe, Japan and North America"the great wave of change“. Significant changes in the composition of the workforce transferred the economic and the social roles of men and women, but also affected matters of health, attitudes to physical activities and sport (McElroy, 2002). As a result of political and economic changes which occurred in the Czech Republic two decades ago, all areas of society started to be restructured. Naturally, this process also included public administration having responsibilities for many areas of the people's lives, including sport. This new way of "public matters provision" started at the beginning of

\footnotetext{
* Faculty of Sport Studies, Masaryk University, Czech Republic.
}

the 1990s and culminated in the period of 20002002.

Together with this process, public administration at lower territorial levels started to constitute rapidly as a basis of democratic, and even more, civic society. The area of sport, in relation to the public sector, has gone through great changes both in structural and process terms. The relations between the sphere of sport and the public sector are naturally mutual undergoing gradual changes (Hobza, Cikl, 2007). To try to contribute to increasing the knowledge of the present-day position of sport in the Czech Republic it is useful to search a relevant relations of municipalities and their policie to various levels of sport. The task is to explain how the situation has developed and which position sport has gained in the Czech public administration. And of course, to discuss the situation of sport, means to present position and role of sport activities in different societal 
and demografic parts of society too (Kovár, 2002).

The emancipation process of sports bodies at the beginning of the 1990s, however, also resulted in the necessity of tackling numerous problems related not only to these entities themselves, but to their relation to the all-society environment. Still, however, advisory bodies as well as professional sections gradually started to work there dealing with the national representation of sports, sport for all, research etc. Sport, as it was, was not regulated by any legal code, not even in relation to the municipalities. It was up to the municipalities themselves whether they would integrate the sport sector into their policies at all. The voluntary sector, which until then had stabilized and was looking for partnership and cooperation within its own ranks, also participated in these activities taking the role of a partner. But continual deficiency of conceptual work on the field of balanced position of leisure and top levels of sport is still typical for relevant politics in the Czech Republic (Slepičková, Staněk, 2007).

\section{Sociological Aspects of Physical Activity}

To discuss specific topic of situation of sport in given society means to discuss relevant concepts: sport, excercise, physical fitness:

Sport: An activity involving physical exertion, skill/or eye-hand coordination as the primary focus of the activity, with elements of competition where rules and patterns of behaviour governing the activity are grounded in various incentives like good physical and psychical shape, reasonable way of leisure, performance, victory, records, reward (Sekot, 2008, p. 10).

Exercise: Any structured and/or repetitive physical activity performed or practiced where the main intention is to achive improved physical fitness (Pink, p. 3).

Physical fitness: A set of health (i.e. cardiorespiratory endurance, muscle strength, flexibility) and performance related (i.e. skill, speed, dexterity, mental concentration) attributes that people have in relation to their ability to perform physical activity.
Physical fitness is a complex phenomenon that is difficult to define in the context of health. It can be conceived as a set of attributes that people have or achieve and that relate to the ability to perform physical activity (Casperson et al., 1985). This defined, physical fitness includes discrete components such as aerobic (or cordio respiratory) fitness, muscle strenght, muscle power, flexibility, agility, balance, reaction time and body composition. The physical fitness component usually associated with fitness is aerobic fitness and another components are related to it. Aerobic fitness depends upon pulmonary, cardiovascular and hematological components of oxygen delivery and oxidative mechanism of the exercising muscle. Its efficiency in relation to chronological age depends on cordial output.

In the past, many of our daily responsibilities involved considerable application of human energy. People were forced to be much more involved in physical activity, and physical labour. People typically spent much of the day in a physically active state, such a walking, lifting, and working with the hands. Whereas human motion was once an inescapable part of normal daily routine, today people must consciously appreciate positive physical activities and intentionally to include it as part of their daily practices to maintain good health and balanced physical and mental shape. People in Czech Republic, are in many respects permeated with „busy capitalist rhythm of "post-transformed society" oriented one-sidedly at performance, success, popularity, money, societal admiration. In such milieu endangered and problematic groups of population are busy, stressed, feel the lack of leisure and long car driving and high technology involved top businessman, managers and „workholics“, as well as socially deprived groups as jobless people or ethnic minorities (mostly Gypsies) lacking proper value orientation accenting healthy and sustainable style of life absorbing healthy dietary habits, regular intentional physical exercising, sportive and outdoor activities (Slepičková, Flemr eds, 2007).

The physical activity specialists recommend for adult complete 30 or more minutes of moderateintensity physical activity, preferably on most days of the week. Unfortunately, widely 
circulated health messages have not been effectively translated into increased physical activity among most Czech people. Despite the accepted value of the multiple benefits of physical activity, most people lead sedentary lives, especially as they become middle-aged and older. In such way, general frequency (number of times), duration (the average number of minutes), and intensity (perceived degree to which heart rate is increased) are for most part of population very low (Sekot, 2006, pp. 193-198).

From sociological point of view three categories of physical activities are established

1. No physical activity (no reported activity of any type during the previous two weeks).

2. Regular sustained physical activity (more than five times per week and more than 30

minutes per occasion of physical activity).

3. Regular vigorous physical activity (more than three times per week and performed at more than 50 per cent of estimated age- and sexspecific cardio respiratory capacity).

Physical activity and physical fitness are often used interchangeably but they are not synonymous and before proceeding the terms require clarification. Physical activity is therefore a component of total energy expenditure, which also includes resting metabolism, growth and the thermal effect of food (Armstrong, 2007, p. 27). Another conceptual perspective describes physical activity as any activity that increases health rate via intentional activities done in sports, school activities, playing with friends, or walking to school. In this context we have to remind running, brisk walking, roller skating, biking, dancing, skateboarding, swimming, soccer, basketball, football and surfing"(Currie et al, 2004, p. 91). A common activity target for adult physical activity is the accumulation of 10000 steps per day (Hatano, 1993). The minimum recommended number of steps/day for girls and boys is 12000 and 15000 respectively. In terms of time, the step counts translate to about 120 minutes of daily activity for girls and 150 minutes for boys (Hills et al. 2007, p. 115). Commonly, girls' participation in all forms of physical activity, including sport, rapidly declines during their early high school years, including club-organized sport or physical activities. Regarding the phenomenon of transport to school, it is evident in the North America, Australia and Europe, various transportation surveys show that nearly 50-60 per cent of 5-15 yours old are driven to school in cars, while 30 per cent travel by bus and only 10 per cent walk. The irony is that, where studies have assessed preference to mode of transport to school, children commonly indicate a preference for walking or cycling.

More than 30 methods of estimating physical activity has been identified but the reliability, objectivity and validity of many of these methods have not been fully confirmed. Anyway, on overall level, the data across Europe are remarkably consistent and show physical activity declines with age, at lest through the teen years, and that girls are less likely be physically active than boys. There is no evidence to indicate major differences in the level of physical activity of youth living in Europe in comparison to those in North America. Regarding the aerobic fitness of European youth: There is no convincing evidence to suggest that low levels of aerobic fitness are common amongst European children and adolescents. Recent data indicate an emerging polarization with the difference between fit and unfit young people increasing over time. On a population basis, aerobic fitness is not increasing in line with the increase long term of body mass and therefore maximal performance in activities involving moving body mass is declining. Data from several EU countries are very similar: Boys of all ages participate in more physical activity than girls and the gender difference is more marked when moderate to vigorous physical activity is considered. The physical activity levels of both genders are higher during childhood and decline as young people move through their teen years. Physical activity patterns are sporadic and sustained periods of moderate to vigorous physical activity are seldom experienced by many children and adolescents. The evidence linking habitual physical activity with aerobic during youth is not compelling and young people with different level of aerobic fitness do not necessarily bigger in their physical activity. It is supposable that the habitual physical 
activity of European youth lacks the proper intensity and long time duration. (Armstrong. 2007 , p. 46-47). One primary reason for the deterioration in motor skills is the lack of physical activity in everyday life. In addition the differences with respect to a decreasing overall coordination are more pronounced in children from urban areas than in those from rural areas (Brettschneider, Naul, eds. 2007, p. 292).

Most people know that they need to include more physical activity in their daily lives. Media images of youthful, attractive men and women actively engaged in sport, bookstore filled with the latest exercise manually, and a proliferation of home-based fitness equipment serve as constant reminders of the importance of being physically active. People have been bombarded with messages stressing the significant role physical activity plays in maintaining good health and preventing disease. During the last decades, several national campaigns have helped people to learn about the health benefits associated with physical activity.

At the time being we face increasing amount of reports in the media and scientific literature focusing on adolescents and depict them as a high-risk group: they are allegedly becoming fatter and fatter, supposedly as a consequence of they eat too much, chiefly fat and sugar, spent to much time sitting in front of the computer and of the television, fail to take enough exercising in their daily life and are less physically fit than any generation before them. To find out whether this scenario represents a distorted view or an accurate description of the reality is not easy task. Despite the fact of almost identical and equally alarming reports in the media of all European countries, scientific front has not been able to offer a clear and convincing answer. The relevant data on the overweight and obesity of children and young people are mostly inconsistent as that relating to nutrition, media consumption, physical activity and fitness, and in some cases reflects considerable variance. In particular we can take into account the activities and relevant outcomes of World Health Organisation (WHO) and the International Obesity Task Force (IOTF), who have increased efforts to promote research into the question and to establish guidelines for diagnostics, prevention and therapy of obesity. Also EU
Commission, Directorate for Education and Culture, have tried since 2003 to compile an intercultural comparative analysis of adolescents' lifestyles within EU with the emphasis on lack of physical exercise (sedentariness). An emerging increasing polarization with the difference between active and inactive as well as fit and unit European youth, clustering the risk healthy factors related to low physical activity, low level of effectiveness of dietary programs, correlation of physical activity and fitness, are observed and ascertained in this context (Brettschneider, Naul, eds. 2007).

\section{New Phenomenon - Sedentary Society}

Interest in sedentary lifestyles is largely due to the growing recognition that physically inactive lifestyles are related to the major diseases that plague contemporary societies, above all heart disease, diabetes, and stroke. Diseases associated with sedentary living cost growing amount of health expense, in the rank of billions of Euros. Regarding of decreasing existence of regular physical activity in our lives (more less on global level) is evident in:

* Work (impact of sophisticated technology, automatization, computeraziation etc.)

* Home (electrical appliences in kitchen and garden, personal PCs)

* Transportation (public transport, cars, motobikes)

One of the most important finding regarding to the physical inactivity is an estimation of up to $70 \%$ of illness today is cause by preventable factors (McElroy, 2002, p. 14): The greatest enemy of to the health of the individual is the individual itself. The health implications of sedentary living began, not only in Europe and America, to be addressed. More and more people have tried, but also have failed to adopt healthy lifestyles. To adopt a healthier lifestyle means is to be able to distinguish between basic causes, the factors that are responsible for generating a particular outcome, and surface cause, which are factors that are related to the outcome, even though changes in these factors do not produce corresponding changes in the outcome. Say it shortly: Thus even if we are 
effective in getting people to adopt healthpromoting behaviours such as regular physical activity (e.g. surface cause), as long as the social structure of society remains unchanged (e.g. basic cause) new obstacles are likely to emerge to perpetuate sedentary habits (e.g. accessibility to sport facilities, standard of living, ways of transport, job opportunity, masculinity versus feminity relations etc.).

We know very well that differences among individuals plays in prevention of physical inactivity and sedentary life-style very strong role. Successes or failures in this field are considerably characteristics of individual. The sociologists must look at the walls in which social conditions affect individuals' opportunities for success. In such context we face dilemma of individual/social structure (Wright, 1993). The individual, regarding his or her rights and responsibilities, has chance to respect or not an imperative of healthy nutrition and regular physical activities, or to drink alcohol, to smoke, to eat junk foods and enjoy or not enjoy physical inactivity. The individuals in European context has mostly the solutions for dealing with such alternatives, with existing ways of life, and after all with these health problems have something much with the phenomenon of obesity. If unhealthy behaviours such as eating a poor diet, smoking cigarettes, or inadequate amounts of physical activity are confined to „only“ an aggregate individuals, then these lifestyle behaviours can be seen as personal troubles. The effective remedy would be to enact physical activity programming and other health-promotion programs targeting individuals directly. But the problem of sedentary way of life or phenomenon of physical inactivity is in our cultural setting so pervasive that physical activity takes on the character of public problem. From the societal perspective has been for couple of the last decades more and more evident, that significant improvements in physical activity for many European people (as well for many Americans, for instance) requires us to look beyond individuals to the factors in society that lie out off their control. Most people in general are not conscious and personally responsible enough to overcame their laziness and systematically steadily cultivate and foster fitness, well-being or generally saying healthy way of life.
Beliefs and good intentions are often not enough to compel many to establish patterns of physical activity: Plenty of surveys confirmed the supportive effects of exercise to good health, but failing in endeavour to increase physical activity of mass of people (McElroy, 2002, p. 18). And in addition: Over the past decade, the mass media in developed countries have been increasingly popular as a strategy for delivering preventive health messages, In the context of post-modern information age „hot news“" regarding the concern for health is phenomenon of physical activity as the latest in a long list of health topics found in print and broadcast sources. Ranging from the more traditional television and radio outlets to the more recent proliferation of Internet sources, consumers increasingly rely on the media to supply them with major source of health and exercise information. But mass media at the same time offers in growing measure colourful offer of passive forms of leisure - watching (not practising) sport activities of very popular mass culture with a presentation of top sports with its stars, icons and celebrities. People are increasingly encountering with an epidemic of large scale consumer's confusion. The public confusion concerning the many healthpromoting strategies reflects partly an obsession with health matters, partly existing difficulties by attributing a high degree of certainty to new health findings. Health risks are sometimes exaggerated or improperly explained and factual inaccuracies may by relayed to the public.

To change sedentary behaviour means to face plenty of difficulties. For many people, an engagement in an exercise program can be more difficult than starting one. People who joint exercise programs or start to intentional sport activities believe in the health-enhancing effect of regular exercise, but these beliefs alone are simply not enough to keep more than half of them in the programs for the long time haul. People are initially usually well intentioned setting ambitious goals at the start of a new sportive regiment; but many - or most - of them drop out within demanding process of regular physical activities. Many people have not been able to overcome an extra demands typical for ordinary everyday life, not to be able or to be willing to overcome their laziness, indolence; to face and overcome the personal, social, and 
environmental barriers to exercise, to practise physical sportive activities. People prove frustrations associated with establishing a continuous exercise routine and in many cases quit for it after some time.

Intelligible relations of leisure time and physical activities are on the scene when people are asked why they do not participate in physical activity. As mentioned above, the most common explanation is typically „no time“. Business or career responsibilities and family obligations are the usual justifications for the lack of time in busy day for participation in physical activity. Although certainly important to the explanation, sedentary lifestyles are much more complex than just finding the time to participate. In the spectrum of explanations of physical inactivity is not easy to pinpoint the most credible. Specific more facts play their role in this context: The experts cannot even agree whether people today have more or less leisure time available to them. Without regards to the fact that general agreement on definition or leisure time does not exist too (Sekot, 2006, pp. 167170). The structure and the distribution of the leisure time is today in many instances characterized by frequent, shorter period of free time disperse throughout the day. Free time, for example, is for busy people more likely to occur in several $\mathrm{x}$-minutes blocks rather than for extended periods of time. For people being really involved in physical activity life is worth such shorter periods, to take a walk or use the exercise equipment stashed away in the corner of the room.

For most people, the inability or unwillingness to engage in regular physical activity is likely due to something more. Indeed, the participation in regular physical activity is not a simple matter. To be more active, means for sedentary people to do things that they have not done previously and to stop doing things they have been doing for long period of time. And the benefits of physical activity may take months or even years, but the discomfort are often more immediate. A commitment to physical activity also requires another set of requirements regarding planning, preparation (and in some respects an additional expense too). Anyway:

Participating in physical activity on regular basis requires constant vigilance to overcome the circumstances that impede participation in physical activity (Maddox, 1997).

Although there are certainly many examples of successful programs to change behaviour, the evidence suggests that behaviours change is a very difficult and complex challenge. Numerous factors both individual and environmental moderate the prediction of behaviour from intention. Factors such as accessibility to and availability of resources allow the behavioural intentions to be realized. But we almost permanently in this context face the general problem of individual flexibility, adaptability, endurance of individuals: His or her ability or willingness to utilize an offer of sportive activities or to adopt given circumstance for systematic harmonization physical activities. Somebody needs for sport activity financially and organizationally demanding facilities, somebody is flexible enough to be regularly involved in active sport activities with accordance of changing situations and conditions in the course of time and place. A decision to participate reflects the summed effects of all factors that should be considered in the colourful complex of active involvement in physical activities.

To be successful the model needs has to anticipate also the forces outsider the individual, such as economic or environmental. Another popular model of the health promotion is the model of planned behaviour where subjective norms, beliefs about the standards or expectations of others, guide acceptable behaviour: In the context of physical activities an important incentive is appreciation the activity as socially acceptable (Ajzen 1985).

During the 1990s exercise professional have adopted the ,stages-of change"model, which acknowledges that individuals progress through a series of changes as they want to adopt new behaviours (Prochaska, DiClemente, 1994). Under existing complex of contemplation, preparation, action, maintenance and termination, the process of physical activities in the context of health promotion assumes readiness to change within the individual and not readiness of the social environment. Just in such framework the evidence suggests that behaviour change is a very difficult and complex challenge: Numerous factors both 
individual and environmental moderate the prediction of behaviour from intention. Unfortunately most health interventions, one way or another, rely on changing attributes associated with the individual. With his or her willingness to overcome laziness, physical exertion and some level of discomfort.

The phenomenon of obesity and a social analysis of inactivity is permeable with problems of individual responsibility and social change. The explanation for why contemporary people deal with health issues and obesity is in many respects explained by the concept of „rugged individualism“. Whilst in developed affluent societies certain values are central to culture - individuality, success, material comfort, and social and individual advancement, in post-communist countries very strong position play insatiable consumption of consumer goods, an admiration of celebrities, passive use of leisure time. But not enough is for example in Czech republic - deeply rooted, respected and admired the belief system that those who work hard and take advantage of opportunity will be rewarded with a good life of material comfort as well as good health. As a consequence - individual responsibility for personal good shape, fitness and good health is not generally practised, respected and cultivated. People here not enough take in their account that failure in personal life is rather caused due to individual casual agents than the social ones.

Regarding body, body shape and phenomenon of obesity: When the individuals fail to maintain the right weight and shape, when they are even obese, it is easy to conclude that he or she lacks the conviction or self-control to maintain healthy behaviours. Such response reflects a major implication of individualism: Individuals are able to make choices. But lifestyles build around change at the individual level are mostly in link with societal and environmental conditions that help generate the behaviours. The importance of physical activity for good health is indisputable, but at the same time broader social environment plays important role too:, An overemphasis on changing the behaviours of individuals exaggerates the individuals' capacity to bring about significant improvements in health“(McElroy, 2002, p. 26).
Phenomenon of obesity exists in broad frame of social structure that includes interactions with family, friends, workfellows. It also encompasses social institutions such a families, schools, workplaces, sport clubs, voluntary organizations, which help to shape our values and attitudes. The value orientation, so important for attitudes to physical activities and health, is significantly build in „face to face“ surroundings, such as family, work organization, schools, neighbourhood, and community (including growing influence of various kinds of mass media) In such sort of physical environment are plenty of opportunities to be physically active. Vice versa the social environment, which includes the way people come together to interact socially, contributes to promote changes to their physical environment. Distal social factors are permeating society in the context of given positions in the social and economic hierarchy. From the perspective of physical activities such factors could play some role in the context of socio-economic status, income inequality, discrimination, racism, sexism or heterosexism. Societies accenting performance, success, media admiration of celebrities, are prone to support formal professional sport activities as a sport arenas and fitness centres. Societies accenting healthy life style and sport for all are oriented in building of health clubs, exercise classes, and work-site fitness facilities, in addition to bike paths, tennis courts, and jogging trails. Nearby exercise facilities can serve not only for to encourage regular physical activity, but also can serve as visual reminders that prompt sportive activities, as a reducer of the physical barriers associated with exercise, such as transportation troubles and travel time.

Physical features of the local environment play very important role in measure of the level and quality of participation in physical activity. Lack of recreational open air spaces, accessible school facilities, health clubs, poorly maintained cycling paths or playing grounds, are factors reinforcing opportunity to reproduce sedentary way of life. It is not surprising that in our cultural settings the amount of decline in leisure-time physical activity is predominantly largest among people residing in the poverty areas - in Czech context mostly in Gypsy ghettos. It is more and more evident that the 
abilities of people to participate in physical activities depend on changing the features of their physical environment that give them more healthy options.

Social environments consists of the non physical products of human interaction, which include the ideas and values shared by members of a particular group as well as they come together to participate. Social connectedness play indispensable role in matters of good health: Meaningful social relations contribute to harmonic personality and in consequence also enhance positive health behaviour and physical shape. In several medical studies, social connection has been associated with improvement in behavioural health factors, such as smoking cessation, compliance to medical regiments, control of diet, and physical activity (Kawachi, et al., 1996). The synergistic roles of physical and social environments affect participation in physical activity. Resulting behavioural settings can promote physical activity when they provide the physical space (e.g., sports facilities, health clubs, bicycle paths, swimming pools) along with the social resources that we draw upon to interact with others community-policing programs.

Phenomenon of obesity and physical activity is many-side affair connected with the concept of a healthy life style. Life style behaviours in general is significantly determined by social status, by professional position, by amounts of money and the quantity of property. Those who have the means may choose to be physically active; those lacking the financial resources cannot freely to choose to be involved in regular sportive activities. Unhealthy behaviours, including sedentary lifestyles, are influenced by people's position within social groups and broad social forces in the general society. But decision about whether to adopt a healthy lifestyle reflects personal attitudes and value preference and thereby includes an aspect of personal choice. But factual personal choice has many preconditions with social position and cultural quality of people and with the access to resources of full range of choices regarding sportive activities. We can conclude: Healthy lifestyles are patterns of voluntary behaviours based on choices from options that are available to people according to their life situations (Cockerham, Rutten, Abel, 1997).

In developed post industrial countries the members of upper and middle class by way of active lifestyle mostly reflect their value self identity accenting balanced share of an intellectual and a physical activities. It is a tendency to evaluate good health as a personal value to be sought and cultivated for one's own benefit, such as experiencing increased vitality and enjoyment of life. This tendency is nowdays reflected in concept active health, popularized thanks to American health specialist Kenneth Cooper. Lower-class individuals, with reference to the nature of their work activities and income, are less optimistic to ovoid poor health and thus are less apt to participate in systematic health promoting activity. Anyway, members people in lower socioeconomic position experience poorer health and higher disease rates when compared with more privileged social groups.

Individuals and their own behaviours, either than society and its social structure, are seen as the primary solution for dealing with changing health-compromising behaviours such a sedentary lifestyles. The values associated with our social institutions such as the traditional nuclear family, achievement standards on schools and a disease-centered health care system are tied to the traditional model class values that have created serious gaps in the health status and physical activity patterns among many contemporary Czech people. Creating a more physically active society must also include reinventing social norms associated with individuals working together for collective change: „A thriving civil society depends on a people's habits, customes, and ethics attributes that can be shaped only indirectly through conscious political action and must otherwise be nourished through an increased awareness and respect for culture (Fukuyama, 1995 , p. 5). Such assertion is in everyday reality confronted with very stimulating fact that societies rely on social institutions, such a family and school, to pass on successive to set via a process of socialization a set of values, expectations, and solutions from which individuals can draw making their way through life. 
Just by force of relevant ways of institutionalization the individuals become organized in standardized form over time and similar from one situation to another, their social interactions and behaviour reflects given sets of fundamental values and cultural patterns. Unfortunately, many of our key institutions fail to relay the importance of physically active lifestyles. Many members of working-class involving in physical labour, both job and family related, need and prefer to rest to compensate for this labour. Model-class families are frequently used to cope with tensions arising from busy lives and the difficulties in adhering to health-promoting behaviours. The "rest ethic" is also rather typical for aging people and people near retirement age. They view active lifestyles included regular physical activity as something reserved for the young. Here the school systems and health care systems are not efficient enough to provide basic skills for a lifetime commitment to physical activity and accenting the idea that it is better to prevent diseases than curing them.

Way of life, structure of values, nature of human relations, social feelings are the factors contributing to levels and nature of social connectedness. Social scientists in general have noted the disappearance of "civically engaged" society and the loss of many people's connections with the life of their communities. Contemporary post modern society characterized with intermediate mass media's nature of human relations reflects the decline of active engagement in community activities. Today's people are in decline to participate in organized groups, ranging from voluntary organizations, sport clubs to decreased interest in school service groups. People's propensity to participate in fewer voluntary organizations in favour of isolating activities reflects general feature and tendency in our cultural settings. Such "desocializing phenomenon" is reflected in declines and lack of membership in physical activity organized neighbourhood local groups. Resulting effect is apparent: people are more and more individualized, loosing beneficial impacts of community activities, involved in passive way of life lacking proper level of physical activities and active sport (McElroy, 2002., Sekot, 2006).

\section{Socioeconomic Indicators of Physical Activity}

Although prospects for revitalization of physically active society are questionable, we are obliged to change or modify a long standing resistance to exercise among our contemporaries. Post industrial (or) post-modern society characterized in involvement in momentary short term experience, refusing traditional and long term values, is not good place or cultural context for a transformation to physical activity both at the societal and individual level. Such transformation will be filled with false stars and obstacles, facing innumerable barriers. These barriers (except general one's inborn individual laziness and indolence) range from political and legislative opposition to struggle for limited resources with other health concerns and media indifference to social explanations for our physical activity problems. Public policy makers have not sufficient attention to public and health preventive medicine and healthy lifestyles. We live in situation when most people agree that healthy lifestyles are a fundamental good for individuals and society. But sedentary life style imposes many various another subjects, costs and negative impacts also on people not themselves directly engaged in risky health behaviours: Strong smoking and sedentary life style of one member of the family could induce emotional stress for rest of the family or may cause individual financial hardship related to loss of job or overwhelming medical costs. From strictly economical point of view, sedentary lifestyles costs billions of health care and lost wages are contributing to economic drain on society as a whole. Another problem is related to the question how far the national physical activity agenda can go in regulating personal behaviours: People do not want to be told what to eat, what to drink, and how much to exercise. Anyway, our chance to achieve a physical active society could be improved if we can overcome the challenges of truly healthy lifestyles available to all members of society, or at least for most part of society.

Physical activity is a complex behaviour. Any activity can be described in terms such as intensity, frequency and duration, and these dimensions must be considered. An assessment methodology should also consider inactivity, 
such as time spent sitting. Physical activity can be related to work, transportation, home and leisure time. The activities at either of these domains may have specific health consequences, and advanced monitoring should also consider these. To present most important results of existing research data it is possible to conclude (Frömel K., Bauman S. et al., 2006):

Growing age of population (men and women too) decreases number of week days and volume of time devoted to physical activity.

Men in general are more involved in physical activties comparing with women.

Growing age decreases existing differences in intensity of physical activity between men and women.

Medium level of physical activity and walking is distributed in age groups and gender groups relatively evenly.

Walking is most frequent form of physical activity in Czech population.

Regular monitoring of level and tendencies of physical activity of population is integral part of monitoring of health situation and life style of population.

The phenomenon of obesity in the context of physical activity is strongly connected with the area of teaching of physical education on given level of school. One of the most important role for acquiring proper habits and patterns regarding regular lifelong physical sportive activity play primary and secondary schools. Research in such context accents a necessity to improve attractive and emotively experienced aspects of physical education to improve high competence of kinetic physical activities for lifelong body and healthy care (Rýgl 2006).. At that time the importace of strict ,marking“ of sportive performance is not recommended more attention is concentrated for to support of individual ability to be regularly involved in physical/sportive activities.

\section{General conclusions: What (Czech) society expects from sport?}

The most critical policy area on physical/sportive activity in European context is the sole fact of sedentary nature of contemporary society. It is evidently openly bitterly accented that the development of a sedentary life style as the result of a socialization process towards the physical inactivity developed in youth and continued into adulthood. Social analysis of inactivity and patterns of sedentary living conclude that in the Czech Republic summarize very high level of prestige of sport and sportive activities in Czech society. But at the same time it was confirmed generally known fact that the significant part of population its positive attitude to physical sportive activities does not realize in practical personal everyday life in the form of regular physical or sport activities. People in the Czech Republic, are in many respects permeated with „busy capitalist rhythm of "post-transformed society" oriented one-sidedly at performance, success, popularity, money, societal admiration. In such milieu endangered and problematic groups of population are busy, stressed, feel the lack of leisure and long car driving and high technology involved top businessman, managers and "workaholics", as well as socially deprived groups as jobless people or ethnic minorities (mostly Gypsies) lacking proper value orientation accenting healthy and sustainable style of life absorbing healthy dietary habits, regular intentional physical exercising, sportive and outdoor activities (Slepičková, Flemr eds, 2007).

It is a priority to develop and pilot suitable flexible tools that will enable public health researchers and decision-makers to assess the potential impacts of proposed policies on dietary intake, physical activity level and obesity throughout Europe using a common methodology, and to assess the potential effects on the distribution of those impacts within the population (that is, issues of equity and impact on specific vulnerable groups).

Mutual relations of sport and society are mostly and visibly reflected in mediated television top sport events. In this context we face typical reflection of passive consumerism of sport as an important part of mass culture: people (society) expect from sport top performance, exciting show compensating monotonic course of everyday life. Society also found in top sport refreshing source of patriotism and medial celebrities, icons and heroes as a target of mass admiration in situation of their absence in the 
rest of society (mostly in politics). The existence of sedentary way of life detracts general level of physical/sportce activities in everyday life of mass of people; growing importace of active way of life and human health improve phenomenon of individual responsibility for human wellbeing. People responsible for his or her physical and psychical good shape expect from sport an indispensable source of wellbeing, respect of their surroundings, and - the last and not least - his or her self-respect.

The general frame of our discussion on mutual relations of sport and society postulates for the governmental institutions to search in the field of sport the real opportunities for active sportive activities for older population, to test relevant situation in self-contained programs for active recreational sport for all groups of population in broader conntext of versatile process of socialization (Sekot, 2008a, pp. 19 - 30). The real chances of school teaching of physical education is to contribute to long-life interest in active physical activities. High level of political will and leadership are required to achieve a decrease in obesity prevalence. All relevant state sectors and levels should play a role in support of sport as a form of active way of life: the new horizonts for civil society are here outlined. In mass society just the media have an important responsibility in propagation and dissemination of health life-styles.

To discuss a phenomenon of physical activity means in such perspective to accent changing nature of lifestyles and leisure time activities that have adopted new forms, contents and meanings. The world of sport and physical activities is also changing all the time in numerous new sport disciplines and activities which are be chosen by growing proportion of people. It could be expected that these changes would affect also the socialisation situations and environments of physical activity:

1. The Czech situation must be prepad for specific situation of enthnical minorities (mostly Romany populations) reflected on the level of their attitude to physical and sportive activity too. In traditional Romany culture the positive attitude to sport is derived from relevant value attitudes of majority society. Mostly young generation of this minority appreciate sport in positive way, thanks to peers and school education. Despite such positive tendency only $14 \%$ of gypsy youth are involved in regular sportive activities - mostly in football, jogging, biking, swimming and dancing (Hastrmanová, Houdek, 2007). Also the 9-11 old pupils of practical elementary schools are not properly and proportionally involved in extracurricular movement activities. Just $19 \%$ of them participate in organized physical activities, compared with 55 per cent of children from ordinary elementary schools.

2. Presented structure of attitudes to sport activities reflects given social and cultural situation in Czech post-reformation setting: People are not consistent enough to overcome their laziness, are too much busy, too much involved in everyday economic problems, not properly appreciated and enjoying refreshing impact of regular physical activities compensating many-sided stress of societal life. But we also take into account the fact, that people are prone to declare an absence of leisure as substitutional reason. Relevant data reflects in Czech population growing tendency of passive attitudes to sport. Physical inactivity is justified with absence of leisure, absence of meaningful motivation and an existence of healthy problems. $40 \%$ of "programmatic physically inactive" acknowledge substantial aversion to physical activity, $28.5 \%$ declare healthy problem and $20 \%$ an absence of leisure. Only marginally is declared absence of sport facilities and financial obstacles (Slepička, Slepičková 2002).

3. To discuss most results and informations on tendencies in the field of physical activities means to conclude that growing age of population (men and women too) decreases number of week days and volume of time devoted to physical activity. Men in general are more involved in physical activities and active transport (cycling, walking) comparing with women.

4. Nowadays physical education is defined as the process aiming at preparation of children and young people for participation in physical culture (tourism, recreation, sport). It is also understood as the foundation of physical culture. Physical education in its humanistic version is understood as "an education of man 
for the care of the body". Humanistic aspects relating to physical education accent intentional activity aiming at forming positive attitudes towards the body, familiarizing a person with the world of physical culture consisting in shaping attitudes towards the body and the values of physical culture, an education for the values of the healthy body, an education of the personality for the care of the body., preparing children and young people for taking responsibility for health, fitness and the beauty of the body after competing education.

5. Social environments consists of the nonphysical products of human interaction, which include the ideas and values shared by members of a particular group as well as they come together to participate. The synergistic roles of physical and social environments affect participation in physical activity. Resulting behavioural settings can promote physical activity when they provide the physical space (e.g. sports facilities, health clubs, bicycle paths, swimming pools) along with the social resources that we draw upon to interact with others community-policing programs.

6. Phenomenon of physical/sportive activity is many-sided phenomenon connected with the concept of a healthy life style. Life style behaviours in general are significantly determined by social status, by professional position, by amounts of money and the quantity of property. Those who have the means may choose to be physically active; those lacking the financial resources cannot freely to choose to be involved in regular sportive activities. Unhealthy behaviours, including sedentary lifestyles, are influenced by people's position within social groups and broad social forces in the general society. But decision about whether to adopt a healthy lifestyle reflects personal attitudes and value preference and thereby includes an aspect of personal choice. But factual personal choice has many preconditions with social position and cultural quality of people and with the access to resources of full range of choices regarding sportive activities.

We can conclude: Healthy lifestyles are patterns of voluntary behaviours based on choices from options that are available to people according to their life situations. In developed post industrial countries the members of upper and middle class by way of active lifestyle mostly reflect their value self identity accenting balanced share of an intellectual and a physical activities. It is a tendency to evaluate good health as a personal value to be sought and cultivated for one's own benefit, such as experiencing increased vitality and enjoyment of life. Lowerclass individuals, with reference to the nature of their work activities and income, are less optimistic to ovoid poor health and thus are less apt to participate in systematic health promoting activity. Anyway, members people in lower socioeconomic position experience poorer health and higher disease rates when compared with more privileged social groups.

7. Phenomenon of physical activity and sport is closely related to urbanisation of sports facilities. In such context it is useful to describe and analyse the most important milestones in the history of city-planning (urbanisation) in the area of sport facilities. The rapid housing and industrial development is resulting in numerous urban-architectural and moreover sociological issues. Sport facilities planning, creating, developing and managing should be considered to be one of the strategic points in public (administration) on both the local and state level (Flemr 2007).

Even the preliminary results of presented research data and pilot studies imply that the individual municipal authorities in the pertinent town areas attach a diametrically different importance to sport and sporting activities. A large difference is already visible in the managing of sport and sporting activities within the organizational structures of the municipal authority. The most critical policy area on physical/sportive activity is the sole fact of sedentary nature of contemporary society: Very high level of prestige of sport and sportive activities in Czech society is incompatible with very low level of practical regular physical or sport activities.

\section{References}

1. Ajzen, I. (1985). From intentions to actions: A theory of planned behaviour. In Kuhl, L., Beckman, L (eds.). Action control: From cognition to behaviour (pp. 11-39). New York: Springer-Verlag. 
2. Armstrong, N. (2007). Physical fitness and physical activity patterns of European youth. Obesity in Europe. Young People's Physical Activity and Sedentary Lifestyles. Berlin, Oxford: Peter Lang.

3. Brettschneider, W.D., Naul, R. (eds.) (2007). Obesity in Europe. Young People's Physical Activity and Sedentary Lifestyles. Berlin, Oxford: Peter Lang.

4. Casperson, C.J., Powel, K., Christenson, G. (1985). Physical activity, exercise and physical fitness: Definitions and distinctions of healthrelated research. Public Health Reports, 100, 126-131.

5. Cockerham, W., Rutten, A., Abel, T. (1997). Conceptualizing contemporary health lifestyles. Sociological Quarterly, 38, 321-342.

6. Cregan, K. (2006). The Sociology of the Body. London: Sage.

7. Currie, C. et al., (2004). Young peopleś health context. HBSC.

8. Flemr, L. (2007). Podmínky pro aktivní životní styl dětí perspektivou pedagogů tělesné výchovy. Aktuální otázky sociologie sportu. Praha: Karlova univerzita.

9. Fořt, P. (2004) Stop dětské obezitě. Praha: Ikar.

10. Frömel, K. et al. (2004). Physical activity of men and women 18 to 55 years of age in Czech Republic. In. F. Vaverka (ed). Movement and Health. pp. 169-173. Olomouc: Univerzita Palackého.

11. Frömel, K., Bauman, A. et al. (2006). Intenzita a objem pohybové aktivity 15-69 leté populace České republiky. Česká kinantropologie. Vol. 10, č. 1, c. 13-27.

12. Fukuyama, K. (1995). Trust: The social virtues and the creation of prosperity. New York: Free Press.

13. Hatano, Y. (1993). Use of pedometer for promoting daily walking exercise. Journal of the International Council for Health, Physical Education and Recreation. 29, pp. 4-9.

14. Hastrmanová, Š., Houdek, L. (2007). Romské etnikum a sport: Percepce, prŕnosy a omezení. Aktuální otázky sociologie sportu. Praha: UK FTVS.
15. Hobza, V., Cikl, R. (2007). Subvenční politiky ve sportu a tělovýchově $\mathrm{v}$ České republice. Česká kinantrolologie. Vol. 2, p. $67-$ 82.

16. Kawachi, I., at al. (1996). A prospective study of social network in relation to total mortality and cardiovascular disease in men in the USA. Journal of Epidemiology Community Health, 50, 245-251.

17. Kovár̆, R. (2001). Tělesná aktivita, tělesná zdatnost a zdraví. Česká kinantropologie. 1, s. 49-54.

18. Maddox, J. (1997). Habit, health, and happiness. Journal of Sport and Exercise Psychology, 19 , 331- 046.

19. McElroy, M. (2002). A Social Analysis of Inactivity. Champaign, IL: Human Kinetics.

20. Pink, B. (2008). Defining Sport and Physical Activity: a Conceptual Model. Cambera: Australian Bureau of Statistics.

21. Prochaska, J., DiClemente, C. (1994). The transtheoretical approach: Crossing traditional boundaries of change. Homewood, Il: Dorsey Press.

22. Rychtecký, A. (2007). Active Lifestyles of Young People - Benefits and Outcomes. Obesity in Europe. Young People's Physical Activity and Sedentary Lifestyles. Berlin, Oxford: Peter Lang. p. 199 - 218.

23. Rýgl, P. (2006). Tvorba školních vzdělávacích programů pro oblast tělesné výchovy na základní škole. Česká kinantropologie, Vol. 10, no. 2, pp. 29-45.

24. Rzewnicky, R. (2003). Health Enhancing Physical activity. Measurement and determinant of daily activity at home, work, travel, and leisure. Leuven: KU Leuven.

25. Sekot, A. (2006). Sociologie sportu. Brno: Masarykova univerzita a Paido. Sekot, A. (2008). Physical Activity Versus Obesity. Educatio Artis Gymnasticale. vol.3, no. 3, p. 51 $-72$

26. Sekot, A. (2008a). Sociologické problémy sportu. Praha: Grada Publishing.

27. Slepička, P., Slepičková, I. (2002). Sport z pohledu české společnosti. Česká kinantropologie, no. 1, pp. 7-23. 
28. Slepičková, I., Staněk, M. (2007). The impact of public administration reform on sport policy in Czech Republic. Local Sport in Europe . 4th eass Conference Proceedings.

29. Staněk, M., Flemr, L. (2007). The role of local authorities of Czech cities in support of sport: A case studyof the capital city of
Prague. Local Sport in Europe. EASS 4th Proceedings.

30. Wright, S. (1993). Blaming the wictim, blaming society or blaming the discipline: Fixing responsibility for poverty and homelessness. Sociological Quarterly, 34, 1-16.

Aleš Sekot is Professor at the Faculty of Sport Studies and the Faculty of Education at Masaryk University, Brno, Czech Republic. He discursed at several universities - Portugal, Spain, Turkey, Bulgaria, His fundamental interest is oriented to the broad frame of sociology of sports; published in comprehensive monographies (2003, 2006, 2008, 2010). He publisded about 200 articles, essays and books on sociology, social pedagogy and sociology of sports. Newly turned his attention, besides negative aspects of top sports - aggression and violence on the footballl stadiums, also to mutual relations physical/sportive activities and obesity in context of sedentary society. 